\title{
Redistribution, Fiscal Competition, and the Politics of Economic Integration*
}

\author{
Anke S. Kessler ${ }^{\dagger}$ \\ Department of Economics \\ University of Bonn \\ Adenauerallee 24-42 \\ 53113 Bonn \\ Germany
}

\author{
Christoph Lülfesmann \\ Department of Economics \\ University of Bonn \\ Adenauerallee 24-42 \\ 53113 Bonn \\ Germany
}

Gordon Myers

Department of Economics

Simon Fraser University

8888 University Drive

Burnaby BC, V5A 1S6

Canada

October 1999

\footnotetext{
${ }^{*}$ We are grateful to various participants of seminars at Bonn and Heidelberg for helpful comments and discussions. Anke Kessler and Christoph Lülfesmann wish to thank the Haas School of Business at UC Berkeley and Simon Fraser University for their hospitality. Gordon Myers wishes to thank the Universities of Essex and Bonn for their hospitality. Financial support by the German Academic Exchange Service ('Hochschulsonderprogramm III'), the Deutsche Forschungsgemeinschaft through SFB 303 at the University of Bonn and SFHCR is gratefully acknowledged. Remaining errors are our own.

${ }^{\dagger}$ Corresponding Author. e-mail: kessler@wipol.uni-bonn.de, phone: +49-228-739246, fax: +49228-739221.
} 


\begin{abstract}
The paper examines the redistributive consequences of the economic integration of factor markets. We consider two countries that redistribute income among their residents. The social benefits in each country are financed by a source based tax on capital which is democratically chosen by its inhabitants. If either capital or labour is internationally mobile, the countries engage in fiscal competition, i.e., the partial integration of capital or labour markets is detrimental to the countries' redistributive ability. A move from partial to full integration, however, may alleviate rather than intensify fiscal competition, particularly, if the two countries face sufficiently similar economic and political conditions. In such a situation, for example, increased integration of labour markets will soften the incentives compete for mobile capital. As a result, there is more redistribution in equilibrium and a majority of the population in each country is strictly better off.
\end{abstract}




\section{Introduction}

In the twentieth century, the world economy has experienced a movement toward ever increasing economic integration. As new technologies have reduced migration and communication costs and institutional or political barriers to mobility have been removed, the mobility of goods, services, capital and - to a lesser extent - labour, has grown rapidly. While the efficiency gains from common markets are undisputed, economists and practitioners alike have expressed their concern with regard to the implications of this development for the ability and the willingness of countries to provide public services and to pursue redistributive policies at the national level. The competition for mobile capital, in particular, is considered by some as one of the greatest dangers to the survival of the welfare state. Sinn (1994), for example, predicts a European Union where "...fiscal competition will wipe out redistributive taxes on mobile factors and reduce the tax system to mere benefit taxation".

This view is supported both by empirical evidence and by the theoretical literature on tax competition. Edwards and Keen (1994) report that on average, corporate tax rates fell by 6 points and top tax rates on interest income by 13 points for OECD countries during the 1980s. ${ }^{1}$ In formal models of tax competition, Gordon (1983) and Wilson (1987) conclude that taxation of mobile capital generates fiscal externalities that result in a suboptimal level of public good provision. ${ }^{2}$ As a consequence, countries could gain from centrally coordinating their national tax policies. Although less pronounced, the integration of labour markets has also been seen as undermining the ability of governments to redistribute income among their citizens. ${ }^{3}$ A recent CEPR report (1993, p. xvi) on subsidiarity within Europe conjectures that "if labour mobility becomes substantially greater, the welfare state could survive only by centralization". A formal argument in this regard has been put forward by Wildasin (1991) who demonstrates

\footnotetext{
${ }^{1}$ The authors also present evidence from Scandinavian countries. In the early 1990's, first Sweden, then Norway, then Finland reformed their capital income tax system, resulting in reduced flat rates in the range of $30 \%$ to $25 \%$.

${ }^{2}$ See also Zodrow and Mieszkowski (1986), Keen (1987), and Wildasin (1988). An extensive survey of the literature on tax competition can be found in Wilson (1999).

${ }^{3}$ Judging from the convergence in interest rates and the volume of capital flows, the integration of global capital markets is reaching a high level of maturity, particularly, in the European Union. Clearly, the same can not be said about the integration of labour markets. However, mobility costs are falling in labour markets as well and one might argue that a defining characteristic of a federation is free migration. This is also true in the European Union where Single Act of the European Union has removed any legal barriers to individual mobility across its member states.
} 
that taxes directed at redistributing income from wealthy to poor households will be inadequately low in a common labour market. The logic is similar to that of tax competition for a mobile tax base: if those who benefit from redistribution are mobile, a fiscal externality arises that governments ignore when determining their local policies non-cooperatively. ${ }^{4}$ Likewise, migration induced inefficiencies also emerge if local public expenditures are financed with revenues from a publicly-owned fixed factor as individuals move in seeking a share of the local rents. ${ }^{5}$

In light of the above arguments, economic integration may seem less desirable than is at first glance suggested even if the potential efficiency gains from common markets are taken into account. The fundamental concern is the consequences of increased integration for redistributive policies and the resulting levels of inequality in our society. This paper provides a new perspective on the redistributive consequences of economic integration. We consider two economically integrated jurisdictions (countries) that pursue redistributive policies at the local level. Integration of factor markets is modeled as the removal of all explicit or implicit barriers to mobility. ${ }^{6}$ In order to analyze the issue of redistribution in a meaningful way, we take individuals to be heterogeneous with respect to their exogenously given endowment of capital. Countries can redistribute income via a lump-sum transfer to each resident financed by a source based linear tax on capital income. The level of redistribution in each country is chosen by majority vote of its inhabitants.

In this framework, we first consider in turn the partial integration of capital and labour markets, respectively. The analysis is taken as a benchmark to compare against the case of full integration where both capital and labour are mobile. Relative to a situation of non-integration (autarky), redistributive taxes are reduced under capital market integration because countries attempt to attract foreign capital in their competition

\footnotetext{
${ }^{4}$ See also Cremer and Pestieu (1996) who discuss the implications of labour mobility on the scope for redistribution within the EU. The possibility that jurisdictions may be forced lower taxes in order to avoid attracting low-income households and repelling high-income households has already been discussed in early contributions such as Musgrave (1969) and Oates (1972). A different view of labour mobility is taken by, e.g., Myers (1990) and Wellisch (1999). In in line with Tiebout (1956)'s seminal presumption that 'voting with one's feet' invokes desirable competition among jurisdictions, these authors show that population migration may enhance the efficiency properties of equilibria. See the discussion in Section 3.

${ }^{5}$ See Flatters, Henderson and Mieszkowski (1974) and Boadway and Flatters (1982).

${ }^{6}$ In particular, the integration of labour markets requries each country to treat foreign individuals equally, i.e. immigrants cannot be discriminated against. In the European Union, for example the equal-treatment principle is guaranteed by the Treaty of Rome.
} 
for the mobile tax base. Expressed differently, because the voters in each country ignore the effect of changes in their tax rate onto the tax base of the other country, a coordinated increase in capital taxes would be strictly beneficial for a majority in each country. A similar result holds if one considers the integration of labour markets in isolation. Raising taxes increases social benefits and, hence, triggers immigration. In their attempt reduce the number of beneficiaries of their national redistributive policy, the countries therefore set taxes relatively low. Again, this argument can be expressed in terms of a fiscal externality if one recognizes that policy induced immigration benefits the voters abroad. ${ }^{7}$

Having identified these two fiscal competition effects that arise from the integration of factor markets, we then ask in a second step whether the conclusions under partial integration carry over to the case of full integration. Our main result is that the two effects need not reinforce but may rather neutralize each other. That is, the composite effect may well be that the problem of fiscal competition is alleviated, in particular if countries are symmetric. In this case, we demonstrate that further integration of labour markets, measured as a reduction in individual mobility cost, always leads to an increase in equilibrium tax rates if capital is mobile as well. As a result, there is more redistribution in equilibrium and a majority of the population in each country is strictly better off. Although this result may seem surprising at first glance, it has an intuitive explanation. The integration of labour markets reduces the incentives for voters to attract foreign capital through lowering national tax rates because it at the same time causes an inflow of labour, which is detrimental to a majority. In other words, the perceived benefits from tax competition are reduced as it causes immigration, precisely because additional capital both raises wages and per-capita social transfers. ${ }^{8}$ Moreover, this effect is strengthened the lower migration costs, i.e., the more pronounced the integration of the labour market.

This intuition is quite general when countries face identical conditions. We also demonstrate, however, that it cannot always be applied to asymmetric countries for reasons we discuss below. ${ }^{9}$ Intuitively, although tax competition is dampened as a result of full

\footnotetext{
${ }^{7}$ See Wildasin (1991) for an extensive discussion.

${ }^{8}$ Of course, a similar argument can be made if one considers a common labour market where capital becomes increasingly mobile. Then, a decrease in social benefits that results in a labour outflow also causes capital to move abroad.

${ }^{9}$ One difficulty that arises is that (in addition to pure fiscal competition) countries may want
} 
integration, high mobility of capital and labour leads also forces countries to converge, both economically and politically. Therefore, countries that had an advantage under partial integration may lose if they remove existing barriers to the mobility of other factors as well. In other words, if countries are asymmetric, the efficiency gains and the gains from reduced inequality resulting from full integration come at a cost - economic and political conditions converge and so do the countries' shares of the economy wide surplus.

Beyond the literature on tax competition mentioned above, the present paper is related to several contributions on fiscal federalism that posit explicit collective choice mechansim to determine political outcomes. Persson and Tabellini (1992) consider a model of inter jurisdictional competition for mobile capital and emphasize the consequences of increasing capital market integration on the policy choice of voters. The authors identify a political effect of higher capital mobility that is shown to partially offset the effects of intensified fiscal competition. Bolton and Roland (1997) also study fiscal competition in a political economy framework. Again, their focus is different and lies in the politico-economic conditions that cause nations to separate into new countries. It is demonstrated that separation cannot always be prevented by granting fiscal autonomy because of tax competition effects. Finally, Scharf and Perroni (1999) examine how competition for mobile capital affects jurisdiction formation. In their model, jurisdictions form endogenously and there exist scale economies in the provision of local public goods. Fiscal competition is shown to result in an enlargement of jurisdictional boundaries and can therefore be welfare improving.

The remainder of the paper is organized as follows. Section 2 presents the basic model and provides an analysis of fiscal competition under the partial integration of capital and labour markets, respectively. Section 3 considers full integration. A final section concludes.

\section{The Model}

The basic framework we use in the analysis allows for both capital and labour to be mobile internationally. As a first step, however, we only consider partial integration to strategically manipulate their factor incomes. The latter incentive is not necessarily reduced by ongoing integration. 
(either capital or labour mobility). The section serves to illustrate the arguments of the existing literature on tax competition and inter-jurisdictional fiscal externalities and formalize them in our model with marjority voting to determine policy outcomes. Subsequently, we consider full integration and show in which sense those arguments must be qualified.

\subsection{The basic framework}

Consider an economy that consists of two countries or regions $j=1,2$, inhabited by continuum of heterogeneous individuals $i$ with mass normalized to one. Individuals derive income from their factor endowments: each individual supplies inelastically one unit of labour and owns $k^{i}$ units of capital. They are free to choose their residency and where to invest their capital. Thus, both labour and capital are internationally mobile. In what follows, we will assume that capital is perfectly mobile, i.e. there are no costs of investing abroad. Labour, in contrast, may be less mobile than capital internationally. This idea is captured by assuming that individuals have to incur a cost $m^{i} \geq 0$ when they emigrate from their home country. The mobility cost $m^{i}$ is derived from the following spatial representation of the economy: suppose individuals reside on the closed interval $[0,1]$ with $i$ representing their initial location. The border is located at $i=\bar{n}_{1}=1-\bar{n}_{2}$ so that all individuals of type $i \in\left[0, \bar{n}_{1}\right]$ initially live in country 1 whereas individuals with $i \in\left(\bar{n}_{1}, 1\right]$ are nationals of country 2 . The migration cost $m_{i}$ can be expressed as a function of an individual's distance to the border $\left|i-\bar{n}_{1}\right|$ which we will take to be linear for simplicity. Hence, $m^{i}=\theta\left(\bar{n}_{1}-i\right)$ for $i \leq \bar{n}_{1}$ and $m^{i}=\theta\left(i-\bar{n}_{1}\right)$ otherwise where $\theta \geq 0$ measures the size of the mobility costs. ${ }^{10}$

By definition, $\bar{n}_{j}$ is the initial size of the labour force in country $j$. It is also equal to its initial share of the total population. We denote country $j$ 's initial capital stock by $\bar{K}_{j}$. In addition to capital and labour, we allow for a third factor of production which is immobile. For ease of exposition, we will refer to this factor as land although one may also think of it any other fixed factor such as natural resources, entrepreneurial input, non-transferable know-how, or infrastructure. Country $j$ is endowed with $\bar{L}_{j}$ units of

\footnotetext{
${ }^{10}$ The mobility costs could also interpreted as representing an 'attachment to home' (individuals have preferences for their home country because of cultural differences) by assuming that the preferences an individual $i$ are given by his consumption, plus a non-pecuniary element $m^{i}$ [see, e.g., Burbidge and Myers (1994)].
} 
this factor which we assume to be publicly owned. ${ }^{11}$

Labour, land, and capital are used as inputs in production by competitive firms to produce a composite consumption commodity $c$. The technology $F(\cdot)$ is identical across countries, any technological differences being captured by differences in the countries' initial endowments of the productive factors. If $K_{j}, n_{j}$, and $L_{j}$ are aggregate inputs in country $\mathrm{j}$, aggregate output is given by $Y_{j}=F\left(K_{j}, n_{j}, L_{j}\right)$.

Assumption 1. The production function $F(\cdot)$ is strictly increasing, concave, exhibits constant returns to scale, and satisfies (subscrips denote derivatives)

a) $\lim _{K \rightarrow 0} F_{K}(\cdot)=\lim _{n \rightarrow 0} F_{n}(\cdot)=\infty$

b) $F_{K L}=F_{K n}=F_{L n} \geq 0$.

Assumption a) ensures that firms employ all three inputs in positive quantities, even if some factors are mobile and the difference in productivity across borders is relatively large. Assumption b) simply states that inputs are (weak) complements in production. In what follows, it will often be convenient to state the relevant variables in per-capita terms. Thus, let $k_{j}=K_{j} / n_{j}, l_{j}=L_{j} / n_{j}$ and $y_{j}=F\left(K_{j} / n_{j}, L_{j} / n_{j}, 1\right) \equiv f\left(k_{j}, l_{j}\right)$ be the per-capita values that correspond to $K_{j}, L_{j}$ and $Y_{j}$, respectively. We denote by $w_{j}$ the wage rate, $r_{j}$ be the return to capital, and $\pi_{j}$ be the return to the fixed factor in country $j$. The first-order conditions of profit maximization imply that each factor is paid its marginal product and that profits are zero,

$$
\begin{aligned}
& r_{j}=F_{K}\left(K_{j}, n_{j}, L_{j}\right), \quad w_{j}=F_{n}\left(K_{j}, n_{j}, L_{j}\right) \quad \text { and } \pi_{j}=F_{L}\left(K_{j}, n_{j}, L_{j}\right), \\
& Y_{j}=r_{j} K_{j}+w_{j} n_{j}+\pi_{j} L_{j} \quad \Leftrightarrow \quad y_{j}=w_{j}+r_{j} k_{j}+\pi_{j} l_{j}
\end{aligned}
$$

Countries pursue purely redistributive policies $\left(t_{j}, g_{j}\right)$ that consist of a) a source based $\operatorname{tax} t_{j} \geq 0$ on each unit of capital employed in country $j$ and b) a uniform per-capita

\footnotetext{
${ }^{11}$ Since we later analyze labour and capital mobililty, it is necessary to allow for third national fixed factor to avoid unrealistic 'buy-out' type of results as discussed in Kuhn and Wooton (1987) and to preserve some locational fixity which is central to the definition of a jurisdiction. By assuming that the factor is owned or controlled by the national government we are also able to study migraton in an environment where the rent-sharing problem under labour mobility discussed in the Introduction is operative. As we will see shortly, one could alternatively assume that the fixed factor is distributed unequally among the population and that it can be taxed. The political process would then imply that the income accruing to owners of the fixed factor is taxed away in full for redistributive purposes. Obviously, the outcome is therefore identical to a situation where this factor is under public ownership.
} 
grant $g_{j} \geq 0$ that redistributes public revenues (including those derived from the fixed factor) among the residents of country $j .{ }^{12}$ Accordingly, the government's budget constraint is

$$
g_{j} n_{j} \leq t_{j} K_{j}+\pi_{j} L_{j} \quad \Leftrightarrow \quad g_{j} \leq t_{j} k_{j}+\pi_{j} l_{j}, \quad g_{j} \geq 0
$$

The policies $\left(t_{j}, g_{j}\right)$ are determined by majority vote of the inhabitants of country $j$. The consumption (net income) $c^{i}$ of an individual with a capital endowment of $k^{i}$ who lives and has invested in country $j$ is

$$
\begin{aligned}
c^{i} & =w_{j}+g_{j}+\left(r_{j}-t_{j}\right) k^{i}, \\
& =y_{j}-\left(r_{j}-t_{j}\right)\left(k_{j}-k^{i}\right), \quad j, h=1,2
\end{aligned}
$$

where the last line follows from $y_{j}=w_{j}+r_{j} k_{j}+\pi_{j} l_{j}$ and by substituting for $g_{j}$ from the budget (3) which will always be binding.

The sequence of events in the model is as follows: In the first stage, the inhabitants in each country $j$ simultaneously vote on the fiscal policy $\left(t_{j}, g_{j}\right)$. In the second stage, individuals simultaneously decide where to invest their capital. In the third stage, they decide on their residency, i.e. whether to move abroad or not. Finally, taxes are collected, residents receive their social benefits and their factor income, and consume. An equilibrium must therefore satisfy the following conditions: a) the implemented tax policies is preferred to any other feasible tax policy by a majority in each country (voting equilibrium), given the foreign tax rate; b) residential and investment decisions are optimal given national redistributive policies; c) markets clear.

Before closing this section it is useful to establish the existence and the general properties of the majority voting equilibrium in stage 1 . Note first that because capital if fully mobile, its net return must be equalized across countries in equilibrium, i.e., $r_{1}-t_{1}=r_{2}-t_{2}$. The preferences of a voter in country $j$ over tax policies $\left(t_{j}, g_{j}\right)$ are therefore unaffected by her decision where to invest her capital. Since we allow for positive cost of migration $\theta>0$, however, this argument does not apply to voters' residential choices. In order to characterize and ensure the existence of a voting equilibrium, it is therefore necessary to assume that they disregard their own residential choice

\footnotetext{
${ }^{12}$ Because individuals do not differ in their labour endowments, taxing labour cannot serve redistributive purposes and can therefore be disregarded. Requiring $t_{j}$ and $g_{j}$ to be non-negative ensures that the effect of factor movements on the utility of individuals can be signed unambigously and is for shortness of exposition only.
} 
when going to the ballot. This assumption on voter myopia eliminates the possibility of preference reversals that may occur when an individual anticipates her decision to emigrate, thereby prompting her to vote strategically in favour of the foreign country. ${ }^{13}$ Then, we see from (4) that preferences are monotonic in individual capital endowments $k^{i}$, irrespective of her investment and residential decisions. It is now straightforward to show that a unique majority voting equilibrium exists even though preferences may not be single peaked (see the Appendix). Furthermore, the unique voting equilibrium in country $j$ is the fiscal policy $\left(t_{j}^{*}, g_{j}^{*}\right)$ that is preferred by the individual with median capital endowment, $k_{j}^{m}$. Let $\bar{k}$ be the average (and aggregate) capital stock in the economy as a whole. We assume in the remainder

Assumption 2. $k_{j}^{m}<\bar{k}, \quad j=1,2$.

i.e., the (initial) distribution of capital is skewed in the sense that the per-capita capital stock in the economy as a whole exceeds the median individuals endowment in each country.

Now suppose that Assumption 2 also holds in each country separately, i.e. $k_{j}^{m}<\bar{k}_{j}$ which is well in line with empirical observations. Assuming that capital owners need not invest their capital anywhere if the returns are negative (free disposal), it follows immediately that under autarky where neither factor is mobile, capital income is taxed away in full: using (4), the solution to

$$
t_{j}^{*}=\operatorname{argmax}_{t_{j}} c_{j}^{m}=y_{j}-\left(r_{j}-t_{j}\right)\left(\bar{k}_{j}-k_{j}^{m}\right)
$$

is $t_{j}^{*}=r_{j}$ since taxes are non-distortionary if capital is not mobile $\left(y_{j}\right.$ and $r_{j}$ are fixed and evaluated at $\bar{k}_{j}$ and $\bar{l}_{j}$ ) and the median voter is endowed with less than the average capital stock. Although this outcome of expropriative capital taxation may be unrealistic, it implies full redistribution and complete equality within a country (though there may still be severe inequality across countries) and thus serves as a useful reference point against which the effects of capital and labour mobility as successive steps of integration can be judged. ${ }^{14}$

\footnotetext{
${ }^{13}$ For an alternative assumption that could be invoked to avoid this problem, see the remark on voter myopia in Section 2.3. below.

${ }^{14}$ One way to restore realism would be to introduce cost of raising public funds [see, e.g., Perotti (1993)] which, however, would complicate the analysis without providing any further insights.
} 


\subsection{Tax Competition for Mobile Capital}

Suppose first that individuals can freely and costlessly invest their capital in either country but there are prohibitively high individual cost of migration. For $\theta \rightarrow \infty$, labour is completely immobile and thus $n_{j}=\bar{n}_{j}, j=1,2$. Since capital is perfectly mobile, its net return must be equal across countries in an equilibrium at the investment stage,

$$
r_{1}-t_{1}=r_{2}-t_{2}=\rho \quad \rho \geq 0
$$

where $\rho$ denotes the common after tax rate of return to capital. Together with $K_{1}+$ $K_{2}=\bar{K}$, the investment equilibrium condition (IE) defines country $j$ 's equilibrium capital stock $K_{j}$ as a function of the policy variables $t_{1}$ and $t_{2} \cdot{ }^{15}$ Using $r_{j}=F_{k}^{j}$ from (1), we can implicitly differentiate (IE) to obtain the investment responses for $\rho>0$,

$$
\frac{\partial K_{j}}{\partial t_{j}}=\frac{1}{F_{k k}^{1}+F_{k k}^{2}}<0
$$

Accordingly,

$$
\sigma_{j}=\frac{\partial r_{j}}{\partial t_{j}}=\frac{F_{k k}^{j}}{F_{k k}^{1}+F_{k k}^{2}} \in(0,1) \quad \text { and } \quad \sigma_{j}-1=\frac{\partial \rho}{\partial t_{j}} \in(-1,0) .
$$

If capital is mobile, raising $t_{j}$ lowers the net return to capital $\rho$ by less than under autarky where the corresponding change would be -1 . However, because each country has some market power, its capital supply does not react fully elastic to changes in $t_{j}$ so that $\frac{\partial \rho}{\partial t_{j}}<0$.

Using (IE), the net income (consumption) of a voter $i$ in country $j$ is given by (4), irrespective of her investment decision. From the previous section, we know that the equilibrium policy in country $j$ is equal to the preferred policy of the individual with median capital endowment in $j$, i.e., it maximizes her net income subject to (IE), and $K_{1}+K_{2}=\bar{K}$. The effect of a change in $t_{j}$ on the utility of the decisive voter $k_{j}^{m}$ in country $j$ is

$$
\frac{\partial c_{j}^{m}}{\partial t_{j}}=k_{j}-k_{j}^{m}+\frac{1}{n_{j}} t_{j} \frac{\partial K_{j}}{\partial t_{j}}-\frac{\partial r_{j}}{\partial t_{j}}\left(k_{j}-k_{j}^{m}\right) .
$$

\footnotetext{
${ }^{15}$ To see why there can be no equilibrium for which $K_{1}+K_{2}<\bar{K}$, note that this would imply $\rho=0 \Leftrightarrow t_{j}=r_{j}=F_{k}^{j}$ and hence, $c_{j}^{i}=\frac{1}{n_{j}} F\left(K_{j}, n_{j}, L_{j}\right)=y_{j}$ for all individuals in country $j$ from (5). Since lowering $t_{j}$ unambiguously increases $K_{j}$, the population in $j$ would unanimously prefer a lower tax rate in such a situation, a contradiction to the definition of equilibrium.
} 
The first term of (8) represents the direct 'redistributive' effect of capital taxation: if the median capital endowment $k_{j}^{m}$ is lower than the per capita capital stock employed in $j$, the decisive voter is a net recipient of public transfers and this effect is positive for a majority of the population. In contrast, if $k_{j}^{m}$ exceeds $k_{j}$, she is a net contributor to the redistributive system in $j$ and the effect is negative for a majority. The second term of (8) is the indirect revenue or 'tax competition' effect: lowering taxes is attractive because of the resulting capital inflow and the corresponding increase in per-capita public expenditures. Finally, the last term captures the composite effect of raising $t_{j}$ on factor prices and, hence, on an individual's gross income and the component of $g_{j}$ financed by revenues from the publicly owned fixed factor. An increase in the tax rate decreases wages and land rents and increases the gross return to capital because less capital is domestically employed. This 'factor price effect' is negative (positive) for the decisive voter if her individual capital endowment falls short of (exceeds) the average capital stock invested in $j$.

From (8) and (7), the first-order conditions of the corresponding program that characterize an interior solution can be written as ${ }^{16}$

$$
\left(1-\sigma_{j}\right)\left(k_{j}-k_{j}^{m}\right)+t_{j} \eta_{k}^{j}=0, \quad j=1,2,
$$

where $\eta_{k}^{j} \equiv \frac{\partial k_{j}}{\partial t_{j}}=\frac{1}{n_{j}} \frac{\partial K_{j}}{\partial t_{j}}$ is the change in country $j$ 's per-capita capital stock as a response to a change in its domestic capital tax rate. Equation (9) defines $t_{j}$ as the best response of the electorate in country $j$ to the policy $t_{h}$ chosen by the other country. The equilibrium tax rates $t_{1}^{*}$ and $t_{2}^{*}$ can be found at a point where the two reaction functions intersect.

Proposition 1. Consider an equilibrium with $\rho^{*}>0$ and $t_{j}^{*}>0, j \in\{1,2\}$. In any such equilibrium, a majority of the population in each country would strictly benefit if both countries cooperatively chose to increase their tax rates.

Proof. Let $c_{j}^{i}\left(t_{1}^{*}, t_{2}^{*}\right)$ be the equilibrium net income (utility) of a voter in $j$ with a capital endowment of $k^{i}$ and consider a change in both tax rates from $t_{j}^{*}$ to $\tilde{t}_{j}^{*}=t_{j}^{*}+d t$, $d t>0$. Since both countries change their tax rate by the same amount, investment decisions are unchanged [see (IE)] and so are factor prices. The corresponding change

\footnotetext{
${ }^{16} \mathrm{An}$ interior solution prevails if neither of the constraints $t \geq 0$ and $\rho \geq 0$ are binding at the optimum.
} 
in a voter's utility is

$$
d c_{j}^{i}=c_{j}^{i}\left(t_{1}^{*}, t_{2}^{*}\right)-c_{j}^{i}\left(\tilde{t}_{1}^{*}, \tilde{t}_{2}^{*}\right)=\left(k_{j}-k^{i}\right) d t
$$

after substituting for $c_{j}^{i}$ from (4). Hence, $d c_{j}^{i}>0 \Leftrightarrow\left(k_{j}-k^{i}\right) d t>0$. In any equilibrium with $\rho^{*}>0$ and $t_{j}^{*}>0$, the equilibrium policies have to satisfy (9). Because the last term in this equation is strictly negative for $t_{j}^{*}>0$, we must have $k_{j}^{*}>k_{j}^{m}$. Hence, $k_{j}^{*}>k^{i}$ for all individuals with less capital endowment than the median voter and $\Delta c_{j}^{i}>0$ for a majority in $j$.

The proposition illustrates that competition for internationally mobile capital generally leads countries to implement tax rates that are 'too low' as compared to the cooperatively chosen tax rates. As a result, there is too little redistribution from the perspective of a majority in each country. Intuitively, fiscal policy in the presence of a mobile tax base has two beneficial external effects on the foreign country. Raising taxes at home causes an outflow of capital which a) increases foreign revenues [the fiscal externality identified in Wildasin (1989)] and b) lowers the price of capital and increases wages and the returns to the fixed factor aborad. From (4),

$$
\frac{\partial c_{h}^{i}}{\partial t_{j}}=\frac{1}{n_{k}} t_{h} \frac{\partial K_{h}}{\partial t_{j}}-\frac{\partial r_{h}}{\partial t_{j}}\left(k_{h}-k^{i}\right)=t_{h} \frac{\partial k_{h}}{\partial t_{j}}+\left(1-\sigma_{j}\right)\left(k_{h}-k^{i}\right)
$$

Clearly, this externality is positive for a majority of the population abroad if $t_{h}^{*}>$ $0 \Leftrightarrow k_{h}>k_{h}^{m}$ in equilibrium. This line of reasoning also explains why the above result only holds for $\rho^{*}>0$ and $t_{j}^{*}>0$. To see why tax rates need not always be below the cooperative solution, suppose $k_{h}<k_{h}^{m} \Rightarrow t_{h}^{*}=0$ for one country $h .^{17}$ Again, it is easy to show that there exist changes in tax rates $\left(d t_{1}, d t_{2}\right)$ which make a majority in each country better off. Yet, this will require $d t_{j}<0$, i.e. the other country's tax rate may be 'too high'. The reason is that the above mentioned externality is negative: the external effect on factor-prices caused by the inflow of capital is negative for the (necessarily capital rich) majority in $h$ (if we allow for $t_{h}<0$, the inflow of capital is also detrimental to the fiscal budget).

Due to Assumption 2, this possibility only arises if the equilibrium is asymmetric. It is therefore sensible to use a situation where countries are identical ex ante as further

\footnotetext{
${ }^{17}$ In the case where $\rho^{*}=0$, it is obvious that the taxation is already optimal from the view of a (capital poor) majority as any further increase in $t_{j}$ would only lead to productive capital being withdrawn from the market (see also footnote 15).
} 
point of reference. In a symmetric equilibrium, ${ }^{18}$ we can use $\sigma_{j}=\frac{1}{2}$ to obtain from (9),

$$
\bar{k}-k^{m}=-2 t^{*} \eta_{k}=0, \quad \eta_{k}=\left[4 F_{k k}\right]^{-1}<0,
$$

where $t^{*}$ is the commonly chosen tax rate and $k^{m}$ is the median capital endowment in each country. Hence, as long as there is an economy-wide desire for a majority to redistribute $\left(\bar{k}>k_{j}^{m}\right)$, we have $t^{*}>0$ and there will be scope for cooperation as shown in Proposition 1.

\subsection{Fiscal Competition in a Common Labour Market}

As a second prelude to our main objective of analyzing full integration of capital and labour markets we next consider a situation where labour is mobile but capital is immobile. Although we do not believe this scenario to be descriptively accurate from an empirical point of view, it allows us to illustrate the arguments of inadequate redistribution in the presence of migration that have been put forward in the literature.

Thus, suppose that capital owners are not allowed to invest their capital abroad (e.g. there are restrictions on foreign investment) so that the capital stock in country $\mathrm{j}$ is fixed and equal to its initial aggregate stock $\bar{K}_{j}$. Individuals can, however, decide to change their residency and move abroad in the migration stage, taking the behavior of all other agents as given. To derive the corresponding equilibrium condition, note first that an individual's migration decision is independent of her capital endowment $k^{i}$. It only depends on her mobility cost and the difference in wages and social benefits across borders. Because the costs of moving are monotonic, a migration equilibrium can be characterized by the marginal individual, $i^{*}$, who is indifferent between residing in either country. Then, all individuals with $i \leq i^{*}$ prefer to live in country 1 while individuals $i>i^{*}$ will live in country 2 . The population sizes in both countries are

$$
n_{1}=\int_{0}^{i^{*}} d i=i^{*} \quad \text { and } \quad n_{2}=\int_{i^{*}}^{\bar{n}} d i=\bar{n}-i^{*},
$$

i.e. country 1's labour force $n_{1}$ also denotes the marginal individual in a migration equilibrium. We can therefore write the equilibrium condition as

$$
w_{1}+g_{1}=w_{2}+g_{2}-\theta\left(\bar{n}_{1}-n_{1}\right)
$$

\footnotetext{
${ }^{18} \mathrm{As}$ long as tax rates are strategic complements (the respective reaction functions are upward sloped) asymmetric equilibria cannot exist if countries are identical. General condtions under which a unique and symmetric equilibrium in tax rates exists are developed in Laussel and Le Breton (1998).
} 
Together with (3), the migration equilibrium condition (ME) implicitly defines country $j$ 's labour force (population size) as a function of $t_{1}$ and $t_{2}$. Let $x_{j}=w_{j}+g_{j}$ be the part of an agent's consumption that is not individual specific and note that

$$
x_{n}^{j} \equiv \frac{\partial x_{j}}{\partial n_{j}}=F_{n n}^{j}-\frac{1}{n_{j}}\left(t_{j} k_{j}+F_{L}^{j} l_{j}\right)-F_{L n}^{j} l_{j}=-\left(\frac{1}{n_{j}} g_{j}+F_{K n}^{j} k_{j}\right)<0,
$$

where the last equality follows from the fact that factor prices adjust to maintain zero profits. As one would expect, an inflow of immigrants reduces wages and the amount of the transfer that is available to the residents of country $j$. Implicitly differentiating (ME) yields

$$
\frac{\partial n_{j}}{\partial t_{j}}=-\frac{k_{j}}{x_{n}^{j}+x_{n}^{h}-\theta}>0 .
$$

An increase in a country's taxation of capital raises social benefits and, hence, triggers immigration which the voters will have to take into account when voting over tax policies in stage 0 .

Under our assumption that voters are myopic with respect to their own residential decision, the preferred tax rate $t_{j}^{*}$ of the median voter in $j$ maximizes (4) subject to (ME). The change in $c_{j}^{m}$ resulting from a marginal increase in $t_{j}$ is

$$
\begin{aligned}
\frac{\partial c_{j}^{m}}{\partial t_{j}} & =k_{j}-k_{j}^{m}+x_{n}^{j} \frac{\partial n_{j}}{\partial t_{j}}+F_{K n}^{j} k_{j}^{m} \frac{\partial n_{j}}{\partial t_{j}} \\
& =k_{j}-k_{j}^{m}-\frac{1}{n_{j}} g_{j} \frac{\partial n_{j}}{\partial t_{j}}-\frac{\partial r_{j}}{\partial t_{j}}\left(k_{j}-k_{j}^{m}\right),
\end{aligned}
$$

after substituting for the expression of $x_{n}^{j}$ and using $\frac{\partial r_{j}}{\partial t_{j}}=F_{k n}^{j} \frac{\partial n_{j}}{\partial t_{j}}$. Similar to the case where capital was mobile, we can decompose the change in individual consumption that arises from a rise in the domestic capital tax rate into the direct redistributive effect [the first term in (11)] and the indirect effect that is due to policy induced migration. The latter is captured by the last two terms: an additional resident (worker) reduces per capita revenues (social benefits) by $\frac{1}{n_{j}} g_{j}$ and the marginal productivity of labour (wage). At the same time the returns to capital and land increase which is, however, not sufficient to offset the fall in wages if $k_{j}>k_{j}^{m}$, i.e., the factor price effect is again negative because $\sigma_{j}=\frac{\partial r_{j}}{\partial t_{j}} \in(0,1)$.

Setting (11) equal to zero gives us the condition for an interior solution for the equilibrium tax rate which defines the reaction functions

$$
\left(1-\sigma_{j}\right)\left(k_{j}-k_{j}^{m}\right)-\frac{1}{n_{j}} g_{j} \eta_{n}^{j}=0 \quad j=1,2,
$$


where $\eta_{n}^{j} \equiv \frac{\partial n_{j}}{\partial t_{j}}$ is the change in country $j$ 's labour force as a response to a change in its tax rate.

Proposition 2. Consider an equilibrium with $g_{j}^{*}>0$ and $\rho_{j}^{*}>0$. In any such equilibrium, a coordinated increase in national tax rates would increase the welfare of a majority of the voting population in both countries.

Proof. The proof is similar to that of Proposition 1. Consider a coordinated change in tax rates with $d t_{1}=\left(k_{2} / k_{1}\right) d t_{2}>0$ such that $\tilde{t}_{j}^{*}=t_{j}^{*}+d t_{j}$ is the new equilibrium tax rate in $j$. Since both countries raise their tax rate in inverse proportion to their equilibrium capital-labour ratios, this change leaves the difference in social benefits and hence, residential decisions and factor prices unchanged in the new equilibrium [see (ME)]. The change in the utility of a voter in $j$ at date 0 is thus

$$
\Delta c_{j}^{i}=c_{j}^{i}\left(t_{1}^{*}, t_{2}^{*}\right)-c_{j}^{i}\left(\tilde{t}_{1}^{*}, \tilde{t}_{2}^{*}\right)=\left(k_{j}^{*}-k^{i}\right) d t_{j}
$$

after substituting for $c^{i}$ from (5). In order to show that $\Delta c_{j}^{i}>0$ for a majority of voters in $j$ if $g_{j}^{*}>0$ and $\rho_{j}^{*}>0$, one can use the same argument as in the proof of Proposition 1. $\square$.

Again, taxes are inadequately low from the perspective of a majority in each country as long as $g_{j}^{*}>0 \Leftrightarrow k_{j}-k_{j}^{m}>0$ and $\rho_{j}^{*}>0$ for $j=1,2$ in equilibrium. Intuitively, each country has an incentive to lower taxes below the cooperative level because doing so causes some recipients of social benefits to leave, thereby increasing per-capita transfers and wages for the remaining population. Expressed differently, a rise in country $j$ 's public expenditures (tax rate) exerts a positive externality on the foreign country through the associated inflow of immigrants at home which is not taken into account [Wildasin (1989)]. Similar to the capital tax competition case, however, this argument requires $g_{j}^{*}>0$ in equilibrium. Thus, there may in general exist asymmetric equilibria where taxation in one country is above the cooperative level ${ }^{19}$ Let us therefore briefly characterize a symmetric equilibrium in a situation where countries are identical ex ante. In a symmetric equilibrium, migration is zero. Imposing symmetry on the reaction functions (12) and substituting for the expressions of $\sigma_{j}$ and $\eta_{n}^{j}$ using (10)

\footnotetext{
${ }^{19}$ This can best be seen in the case where countries' impose negative transfers (head taxes) $g_{j}<0$ which we have ruled out by assumption. In such a situation, regions would like to attract - rather than deter - immigrants.
} 
yields

$$
\bar{k}-k^{m}=\bar{k} \frac{g^{*}}{2 g^{*}+\frac{1}{2} F_{K n} \bar{k}+\frac{1}{2} \theta},
$$

where $g^{*}=t^{*} \bar{k}$ is the common public transfer.

Now assume that labour markets become increasingly integrated, represented by a fall in the cost of migration from $\theta$ to $\theta^{\prime}$, say. Consider a symmetric equilibrium in tax policies where equilibrium policies are characterized by (13). By inspection, the left hand side remains unchanged when considering a new (symmetric) equilibrium at $\theta^{\prime}$. Since the right hand side decreases in $\theta$ and increases in $g^{*}$ a drop in the cost of migration must be accompanied by a drop in the level of public services, holding all other variables constant at their symmetric equilibrium values. Hence, $\theta^{\prime}<\theta$ implies $g^{*}\left(\theta^{\prime}\right)<g^{*}(\theta)$ and consequently $t^{*}\left(\theta^{\prime}\right)<t^{*}(\theta)$.

Corollary. Consider any symmetric equilibrium with $\rho^{*}>0$ and suppose that labour becomes more mobile (increasing integration of labour markets). Then, there exists a new symmetric equilibrium in which a majority of the population in each country is strictly worse off.

As labour becomes more mobile, countries perceive a higher elasticity of immigrants with respect to a change in their level of social benefits (their tax rate). Since immigration is undesirable for a majority of the residents, this effect renders increasing taxes less attractive. ${ }^{20}$ From Proposition 2, the accompanied change in the voter's utility is negative for a majority because a further reduction in social benefits is harmful if those are already at inadequately low levels. We can thus conclude that increasing labour market integration is undesirable from the perspective of the majority of the voting population in each country, at least if countries are symmetric.

\section{A Remark on Voter Myopia}

So far, our analysis has presumed that voters vote myopically with respect to their own migration decision even though they (correctly) foresee aggregate equilibrium migration. As mentioned above, this restriction on voter rationality rules out preference reversals which may arise if individuals know that they will migrate to the foreign country given the domestic policy under consideration at the voting stage, and thus prefer policies that are beneficial from the perspective of their future country of residence

\footnotetext{
${ }^{20} \mathrm{An}$ analogous argument for mobile capital can be found in Wilson (1987) and Wildasin (1988).
} 
(rather than their home country). An alternative assumption that has been used in the literature [Epple and Romer (1991)] to address this problem is that all individuals move and vote simultaneously, while still taking into account policy-induced migration. That is, they do not take the migration decisions of other individuals as given even though these are made simultaneously to their own. Moreover, voting takes place in the country of (future) residence which is somewhat inconsistent with the presumed timing of actions. While it is readily verified that both assumptions yield qualitatively similar results in our model, neither is fully satisfactory which illustrates the conceptual difficulties associated with settings where residential and political decisions are intertwined. One possibility to eliminate those difficulties in our model would be to consider voting under the veil of ignorance. More specifically, suppose individuals when casting their vote know their home country and their own capital endowment but not their future type $i$ which determines the cost of migration. An individual with home country $j$ only knows that $i$ is uniformly distributed over the interval $\left[0, \bar{n}_{1}\right]$ or $\left[\bar{n}_{1}, 1\right]$, respectively. Using the equilibrium migration condition (ME), one can easily show that the expected consumption of a voter in country $j$ from a policy $t_{j}$, holding $t_{h}$ fixed, is

$$
E\left[c^{i} \mid t_{1}, t_{2}\right]=c_{j}^{i}+I_{j} \frac{\theta}{2}\left(\bar{n}_{j}-n_{j}\right)^{2}
$$

where $c_{j}^{i}$ and $n_{j}$ are evaluated at $\left(t_{1}, t_{2}\right)$ and $I_{j}$ is an indicator function which is equal to one if $\bar{n}_{j}>n_{j}$ and zero otherwise. ${ }^{21}$ Under the veil of ignorance, voters rationally maximize expected consumption in their home country, adjusted by the additional benefit they derive from emigration. ${ }^{22}$ Hence, there is now an (additional) positive bias toward emigration. It is now easy to see that our results would remain qualitatively unaffected. ${ }^{23}$

\footnotetext{
${ }^{21}$ From (ME), $x_{j}=x_{k}-\theta\left(\bar{n}_{j}-n_{j}\right)$. Adding $\rho_{j} k^{i}$ on both sides yields $c_{j}^{i}=c_{h}^{i}-\theta\left(\bar{n}_{j}-n_{j}\right)$ (note that it does not matter where the individual has invested her capital). The expected consumption of an individual with home country 1 , for example, is then $E\left[c^{i} \mid t_{1}, t_{2}\right]=\operatorname{Prob}\left\{i \leq n_{1}\right\} c_{1}^{i}\left(t_{1}, t_{2}\right)+\operatorname{Prob}\{i>$ $\left.n_{1}\right\}\left[c_{2}^{i}\left(t_{1}, t_{2}\right)-E_{i>n_{1}} \theta\left(\bar{n}_{1}-i\right)\right]=c_{1}^{i}+I_{1} \frac{\theta}{2}\left(\bar{n}_{1}-n_{1}\right)^{2}$ after substituting for $c_{2}^{i}$ and computing expected migration cost.

${ }^{22}$ Because people leave their home country only if it is beneficial to do so, their utility abroad will exceed their utility at home with the difference being determined by the equilbrium number of people who emmigrated [see (ME)]. As a consequence, if an individual has been assigned very low migration costs (and thus emigrates), her expeced gain over consumption at home is larger, the smaller $n_{j}$.

${ }^{23}$ Clearly, the conclusions under both alternatives are identical for symmetric equilibria and for $\theta \rightarrow 0$. Moreover, the fiscal competition argument under labour mobility (which then translates into lower incentives to compete for mobile capital as we will show below) would be reinforced.
} 


\section{Capital Tax Competition and Labour Market In- tegration}

The previous analysis demonstrated that partial integration (of either capital or labour markets) is detrimental to fiscal policies directed at redistributing income from the wealthy to the poor. At first glance, one may therefore be tempted to conclude that full integration of labour and capital markets intensifies fiscal competition. As will become clear shortly, however, this presumption is misleading. Specifically, this section demonstrates that there are plausible circumstances in which increasing labour market integration alleviates capital tax competition (and vice versa). We consider a situation in which individuals can both choose where to invest their capital, and where to live. Optimal investment and residential decisions require that (IE) and (ME) hold simultaneously, ${ }^{24}$

$$
\begin{gathered}
r^{1}-t_{1}=r^{2}-t_{2}=\rho, \quad \rho \geq 0 \\
w_{1}+g_{1}=w_{2}+g_{2}-\theta\left(\bar{n}_{1}-n_{1}\right) .
\end{gathered}
$$

Together with (3), $K_{1}+K_{2}=\bar{K}$ and $n_{1}+n_{2}=1$, these two conditions define a country $j$ 's capital stock $K_{j}$ and population size (labour force) $n_{j}$ as a function of $t_{1}$ and $t_{2}$. Using the implicit function theorem one can deduce the investment and migration responses to a change in $t_{j}$,

$$
\frac{\partial K_{j}}{\partial t_{j}}=\left[g_{1} / n_{1}+g_{2} / n_{2}+F_{k n}^{h}\left(k_{h}-k_{j}\right)+\theta\right] / D \quad j \neq h, \quad j, h \in\{1,2\}
$$

and

$$
\frac{\partial n_{j}}{\partial t_{j}}=\left[t_{j} / n_{j}+t_{h} / n_{h}-F_{k k}^{h}\left(k_{h}-k_{j}\right)\right] / D, \quad j \neq h, \quad j, h \in\{1,2\}
$$

where $D \equiv\left(F_{k n}^{1}+F_{k n}^{2}\right)\left(t_{1}-F_{k k}^{1} k_{1}+t_{2}-F_{k k}^{2} k_{2}\right)-\left(F_{k k}^{1}+F_{k k}^{2}\right)\left(x_{n}^{1}+x_{n}^{2}-\theta\right)<0$ provided the equilibrium characterized by (IE) and (ME) is stable. ${ }^{25}$

As before, the equilibrium tax policy $t_{j}^{*}$ maximizes the utility (4) of the individual with median capital endowment $k_{j}^{m}$, subject to (IE) and (ME). The change in the decisive

\footnotetext{
${ }^{24}$ Because individuals are infinitisimally small, their decisions have no impact on factor prices and public budgets. Thus, when deciding where to invest, they take the residential choices that are made subsequently as given.

${ }^{25}$ All derivations in this section are relegated to the Appendix. Using standard fix point arguments, it is straightforward to show that a stable migration and investment equilibrium always exists.
} 
voters net consumption can be written as

$$
\frac{\partial c_{j}^{m}}{\partial t_{j}}=k_{j}-k_{j}^{m}+\frac{1}{n_{j}} t_{j} \frac{\partial K_{j}}{\partial t_{j}}-\frac{1}{n_{j}} g_{j} \frac{\partial n_{j}}{\partial t_{j}}-\frac{\partial r_{j}}{\partial t_{j}}\left(k_{j}-k_{j}^{m}\right) .
$$

Again, there is a direct redistributive effect from taxation. Furthermore, because both capital and labour are mobile, there are now two indirect revenue effects that arise from an increase in $t_{j}$. Ignoring the factor price effect $\sigma_{j}=\frac{\partial r_{j}}{\partial t_{j}}$ for the moment, it thus appears that the fiscal competition effects identified in the previous two sections combine so as to render taxation even more unattractive. Of course, this line of reasoning implicitly presumes that the investment and labour force responses are similar to those that prevail under partial integration. Specifically, it requires $\frac{\partial K_{j}}{\partial t_{j}}<0$ and $\frac{\partial n_{j}}{\partial t_{j}}>0$. A closer look at (15), however, reveals that this need no longer be the case. In fact, if $t_{j}>0, j \in\{1,2\}$, then $\frac{\partial n_{j}}{\partial t_{j}}<0$ for $k_{j}<k_{h}$, i.e., a rise in the domestic tax rate now leads to emigration for at least one country $j$. This stands in sharp contrast to our earlier result that in a situation where capital is immobile, increases in a nation's tax rate triggered immigration. The puzzle can be solved by observing that $k_{j}<k_{h}$ also implies $\frac{\partial K_{j}}{\partial t_{j}}<0$ by (14). If capital is mobile, the capital outflow caused by higher taxation (and the corresponding decrease in wages and public benefits) suffices to offset any positive effect on the government's budget that such a raise in the tax rate might have. Expressed differently, precisely because the capital inflow associated with a decline in $t_{j}$ constitutes a negative external effect on the well-being of individuals living in the foreign country, those foreigners with relatively small mobility costs will immigrate.

Unfortunately, it is not possible to derive further analytical results for the general case where the countries are not symmetric. As we have seen in the previous sections, however, the case where countries are ex ante symmetric yields the most clear-cut predictions about the effects of fiscal competition and partial integration on countries' ability to pursue redistributive policies. Let us therefore examine in more detail the symmetric case and consider a situation where countries set a common tax rate $t_{j}=t$, $j=1,2$. Imposing symmetry on the investment and migration responses (14) and (15), we obtain

$$
\begin{aligned}
\left.\frac{\partial n_{j}}{\partial t_{j}}\right|_{t_{j}=t} & =\frac{t}{2 F_{k k}\left(\pi \bar{l}+\frac{1}{4} \theta-t \frac{F_{k l}}{F_{k k}} \bar{l}\right)} \leq 0 \\
\left.\frac{\partial K_{j}}{\partial t_{j}}\right|_{t_{j}=t} & =\frac{g+\frac{1}{4} \theta}{2 F_{k k}\left(\pi \bar{l}+\frac{1}{4} \theta-t \frac{\left.F_{k l} \bar{l}\right)}{F_{k k}}\right.}<0 .
\end{aligned}
$$


Hence, lowering the domestic tax rate never results in (beneficial) emigration as would be the case when capital were immobile. Moreover, the inflow of capital per capita that can be generated by such a policy is now smaller than in the case where labour is perfectly immobile $(\theta \rightarrow \infty)$. To see this, observe that $\frac{\partial k_{j}}{\partial t_{j}}=\frac{1}{n_{j}}\left[\frac{\partial K_{j}}{\partial t_{j}}-k_{j} \frac{\partial n_{j}}{\partial t_{j}}\right]$ using (18) and (17) reduces to

$$
\eta_{k}=\left.\frac{\partial k_{j}}{\partial t_{j}}\right|_{t_{j}=t}=\hat{\eta}_{k} m(\theta)<0
$$

where $\hat{\eta}_{k}=\left(4 F_{k k}\right)^{-1}$ is the corresponding change in a situation where labour is completely immobile (Section 2.2.) and

$$
m(\theta)=\frac{\pi \bar{l}+\frac{1}{4} \theta}{\pi \bar{l}+\frac{1}{4} \theta-t \frac{F_{k l}}{F_{k k}}} \in(0,1) \quad \text { for } \quad t>0 .
$$

As $m(\theta)$ increases in $\theta$ and approaches one as $\theta \rightarrow \infty, \eta_{k}^{j}$ is lower in absolute value, the lower $\theta$ : the per-capita capital stock now reacts less elastically to a change in fiscal changes because of the associated in- or outflow of labour. ${ }^{26}$

Setting (16) equal to zero, imposing symmetry and using our usual notation, we find that a symmetric equilibrium with $\rho^{*}>0$ is characterized by

$$
\frac{1}{2}\left(\bar{k}-k^{m}\right)+t \eta_{k}-2 \pi \bar{l} \eta_{n}=0 .
$$

Observe that for $\theta \rightarrow \infty$, we have $\eta_{n} \rightarrow 0, \eta_{k} \rightarrow \hat{\eta}_{k}$ and this condition reduces to the corresponding condition for the case where only capital is mobile. The second term reflects the combined effect of the induced factor movements on the share of public benefits that is financed through capital taxation, while the third term represents the rent-seeking effect already mentioned in the previous section. As argued above, $\eta_{n}<0$ so that the latter effect is now positive rather than negative and the revenue effect due to $\eta_{k}$ is less pronounced. Since $\eta_{n}$ increases and $\eta_{k}$ decreases in $\theta$, holding all other variables constant at their symmetric equilibrium values, it is straightforward to show

Proposition 3. Consider a symmetric equilibrium with $\rho^{*}>0$ and suppose that labour becomes more mobile. Then, there exists a new symmetric equilibrium in which the common tax rate on capital is higher than in the initial situation, i.e.,

$$
\theta^{\prime}<\theta \quad \Rightarrow \quad t^{*}\left(\theta^{\prime}\right)>t^{*}(\theta) .
$$

\footnotetext{
${ }^{26}$ This is true even though aggregate capital stock responds more elastically to changes in $t$ when labour is mobile. The reason behind this higher elasiticity of the aggregate capital stock is that labour supply, and hence, the marginal product of capital falls (increases) as a response to a rise (drop) in $t$, which discourages (encourages) investment in country $j$ beyond the direct tax effect.
} 
As a consequence, a majority of the voting population in each country strictly benefits from increasing integration of labour markets.

Proof. See Appendix.

The intuition for this result has already been laid out in the preceding discussion: in a symmetric equilibrium, if both capital and labour as factors of production are mobile a unilateral reduction in the domestic tax induces (detrimental) immigration. At the same time, less capital per capita can be attracted relative to a situation where labour is not mobile. These two effects of increasing labour market integration, represented by a fall in $\theta$ work in the same direction: both migration and investment responses tend to discourage tax competition. Provided capital markets are already integrated, the further integration of labour markets is therefore always desirable from the perspective of the majority of the voting population in each country.

Although this strong conclusion requires symmetry of the initial equilibrium, we expect a similar line of reasoning to hold more generally as well. In particular, suppose inadequately low taxation of a mobile factors emerges because (a majority of) the residents in one country benefits from a unilateral tax cut while at same time harming those living aborad. Then, this country will become more attractive relative to the foreign country so that immigration takes place. As long as this additional inflow of labour reduces the perceived gains from tax competition (e.g., because wages and per capita social benefits decrease as additional workers migrate into country $j$ ), the incentives to engage in wasteful fiscal competition are diminished. Put differently, the external effect that one country exert on the other country through its choice of fiscal policy is alleviated because the population moves accordingly. This argument can be most clearly seen for vanishing cost of migration. For $\theta \rightarrow 0$, labour mobility fully eliminates the fiscal externalities that are present, regardless of initial differences in countries factor endowments or national income distributions:

Proposition 4. Suppose $\theta \rightarrow 0$. Then, there exists a unique equilibrium in tax rates $\left(t_{1}^{*}, t_{2}^{*}\right)$ with the following properties. For $j=1,2$,

a) $k_{j}^{*}=\bar{k}, l_{j}^{*}=\bar{l} \Rightarrow w_{1}^{*}=w_{2}^{*}$ and $r_{1}^{*}=r_{2}^{*}$,

b) $\left(t_{j}^{*}, g_{j}^{*}\right)=\left(t^{*}, g^{*}\right)>0$ where $\rho^{*}=t_{j}^{*}-r_{j}^{*}=0$. 
Thus, the unique equilibrium is symmetric, irrespective of initial endowments or the national income distributions. Furthermore, $\rho^{*}=0$, i.e. the returns to capital are fully redistributed among the residents in each country.

Proof. See Appendix.

Proposition 4 is important in several respects. First, it shows that migration helps not only to equalize prevailing economic disparities but also reduces the political differences among countries. Hence, promoting individual mobility can act as a substitute for the harmonization of national tax policies aimed at improving allocative efficiency in a world where capital is mobile. Second, perfect migration allows countries to pursue redistributive policies that are completely adequate from their (equilibrium) point of view. As in autarky, income from capital is entirely taxed away from capital owners and redistributed among all residents in the unique equilibrium. Intuitively, the mobility of individuals makes voters in each country internalize the effects that their chosen fiscal policy has on the other country. In a world where migration cost are negligible, any conflict of interest between voters in each country vanishes because raising their net income at home necessarily involves raising net incomes abroad and vice versa.

The idea that perfect mobility brings about this commonality of interest has already been put forward in the literature on fiscal federalism. In particular, Myers (1990) and Krelove (1992) show that welfare maximizing governments voluntarily propose transfer payments to achieve an efficient international factor allocation in such a situation. ${ }^{27}$ As Bucovetsky (1995) and Wilson (1999) note, however, this result rests on the unrealistic assumption that individuals are identical in every respect. Moreover, inter-jurisdictional transfer payments must be feasible if countries are not identical. Proposition 4, in contrast, allows both individuals and countries to differ in their factor endowments and there is no need for countries to influence the factor allocation through international transfers. The crucial point to recognize is that factor mobility in equilibrium can bring about the degree of symmetry that is necessary to align interests across borders. More specifically, one can show that in any potential asymmetric equilibrium, a majority of voters in the low-tax country strictly prefers to replicate the fiscal policy in the high-tax country because this a) results in an efficient international factor allocation which maximizes per capita output at home and abroad and b) at

\footnotetext{
${ }^{27}$ See also Burbidge and Myers (1994) and Wellisch (1999) for models with positive migration costs where the government has a sufficient set of instruments available to control for immigration.
} 
the same time increases their redistributive benefit from taxation. ${ }^{28}$ Hence, (IE) and (ME) jointly ensure that only symmetric equilibria in which countries set identical tax rates and therefore converge with respect to their per-capita factor endowments can exist. Once this result is established, the unique equilibrium must entail full taxation because any attempt to engage in fiscal competition is self defeating in a symmetric situation where the voters' interest are aligned. ${ }^{29}$ In fact, it is evident that this equilibrium cannot be improved upon from the point of view of a majority in each country without harming a majority in the other country. Expressed differently, this particular international allocation of productive factors and choice of tax policies is on the international 'Pareto frontier' for a majority, constructed by choosing fiscal policies and factor allocations so as to maximize the consumption of the decisive voter in the domestic country, holding the consumption of the decisive voter in the foreign country fixed. ${ }^{30}$ Clearly, this outcome is therefore one possible outcome of a situation where the countries set their tax rates cooperatively.

Finally, the result in Proposition 4 also provides a benchmark against which the residents' utilities in a pure tax- competition situation, that is, without labour mobility, may be compared. In particular, it indicates that potential efficiency and welfare gains brought about by the international equalization of factor returns and the desired level of redistribution also come at a cost: if both capital and labour are perfectly mobile, convergence requires countries in equilibrium to share the economy-wide surplus equally in per capita terms. In other words, any economic advantage that countries might have enjoyed in a situation where labour markets were not fully integrated is levelled out.

\footnotetext{
${ }^{28}$ See the proof of Proposition 4 in the Appendix for a formal argument.

${ }^{29}$ Observe that the mobility of capital is equally crucial for this argument to hold. As Section 2.3 demonstrates, fiscal competition cannot be avoided even if countries are identical and people are perfectly mobile as long as the net returns to capital are not equalized across countries.

${ }^{30}$ This holds regardless of whether or not international transfers can be made. Also, provided $\left(t_{j}, g_{j}\right)$ are the only redistributive instruments within a country, it is easy to see that an allocation cannot be improved upon for a majority if and only if it cannot be improved upon for the decisive voter in each country.
} 


\section{Discussion and Concluding Remarks}

We can now turn to a more detailed discussion of our main results and their implications. Given that capital markets are already fully integrated and fiscal competition prevails, in what situations could we expect a majority in each country to favour labour market integration? Proposition 3 tells us that full integration is often strictly beneficial and never detrimental if one considers symmetric equilibria. This is true even though there are no efficiency gains from common markets in such a situation. Labour mobility serves solely to soften the countries incentives to compete for the mobile capital tax base. If countries differ in important economic or political variables, however, the consequences of further integration are ambiguous. Although a full-fledged analysis has been beyond the scope of this paper, it is possible to identify several effects that work in opposite directions. On the one hand, there are now efficiency gains from a common labour market that can be realized. On the other hand, Proposition 4 suggests that full integration also tends to equalize economic conditions across countries. ${ }^{31}$ Therefore, countries that enjoyed a relative advantage in the situation without population mobility will now be at a disadvantage, ceteris paribus. Some informal insights in this regard may be gained if one draws on existing results from the tax competition literature. For example, it has been shown that countries with small populations win the capital tax competition [Bucovetsky (1991) and Wilson (1991)]. This gain will be lost if the competition is alleviated and countries converge through migration. Thus, ex ante differences in population size can make integration detrimental to the smaller country. ${ }^{32}$ Clearly, a similar argument applies if countries differ in their endowments of the fixed factor which we can also interpret as an existing technology gap. In such a situation, the equilibrium where only capital is mobile will favor the resource-rich and technologically more advanced country because it can attract more capital at a given tax rate. A liberalization of labour markets reduces the gap as workers migrate from the poor to the wealthy country. Hence, even though fiscal competition may be

\footnotetext{
${ }^{31}$ This tendency has been confirmed in the numerical simulations we conducted to investigate the characteristics of asymmetric equilibria under full integration and imperfect labour mobility. The calculations also indicate that full integration maintains its mitigating effect on capital tax competition, albeit less pronouned.

${ }^{32}$ Wilson (1991) compares the outcome under tax competition to the cooperative solution that treats countries symmetrically. Translated to our framework, the latter is the unique equilibrium that emerges under perfect labour mobility (Proposition 4). The author shows that the smaller country may well refuse to implement this outcome. The reason is that the cooperatively optimal symmetric allocation is dominated by the asymmetric but suboptimal allocation under tax competition.
} 
softened, only the poor country unambiguously benefits from full integration.

The central message, however, remains that fiscal competition among countries need not intensify as factor markets are successively integrated. Advocates of a coordination and harmonization of European tax rates conjectured the collapse of the welfare state as countries strive to attract taxpayers and deter the recipients of social benefits in a world where both groups may be expected to be increasingly mobile within the EU. Our results and the accompanying logic indicate that this fear may be unwarranted. Instead, ongoing integration could well have exactly the opposite effect. If the beneficiaries of social policy become mobile as well, wasteful competition for a mobile tax base that helps to finance the welfare state is likely to be diminished. The reason is quite intuitive: unilateral tax cuts intended to attract the tax base will - precisely because they are deemed profitable by the voters in one country at the expense of individuals living abroad - lead to immigration. As a consequence, the country's incentives to engage in such (in equilibrium self defeating) behaviour are weakened. A capital-poor working majority in each country may strictly benefit from higher labour mobility because of its discouraging effect on fiscal competition. We have demonstrated that this line of reasoning is particularly strong if countries are sufficiently similar, either because they already share similar economic and political conditions from the outset, or because increasing integration in equilibrium reduces the differences that prevail.

Also observe that although the exposition focused on capital tax competition accompanied by labour market integration, our conclusions do not depend on the particular factors of production under consideration. Suppose for example that individuals differ in their earning ability (productivity) and counties levy taxes on labour income for redistributive purposes. Then, wealthy individuals are net contributors to the social system while poor individuals are net beneficiaries of social grants. As long as highproductivity labour and low-productivity labour are complementary in production and the poor are in a majority, all of our results apply. The crucial point to recognize is that a rational electorate ceteris paribus only supports a unilateral income tax cuts directed at enticing the rich if the resulting indirect revenue and factor price effects work in the desired direction. But if a low-income majority in one country expects to gain from such fiscal competition, low-income individuals living abroad will have an incentive to immigrate, thereby reducing this gain. Hence, increasingly mobile poor can reduce competition for wealthy taxpayers. 
What is important for our results, however, is that individuals are treated equally everywhere. That is, there is no explicit or implicit discrimination against immigrants. While the equal treatment principle naturally applies within a country, a different picture emerges if one considers an international context. Even in the European Union, informal barriers to free residential choice remain despite the fact that the Union guarantees free mobility and equal treatment in the Treaties of Rome and has since adopted a series of measures directed at promoting mobility across member states. Thus, our non-discrimination assumption may be quite strong. Yet, the observation that it is necessary for our analysis to apply sheds light on the question whether of equal treatment is a desirable principle. From a partial integration point of view, for instance, one could argue that abandoning equal-treatment serves as an instrument to moderate fiscal competition in common labour markets. Our analysis, in contrast, indicates that such measures may well work in a quite different direction: if capital markets are integrated, the discrimination against immigrants in domestic social programs reduces the incentive effect of labour mobility and may thus help to intensify rather than mitigate fiscal competition. 


\section{References}

Boadway, R. and F. Flatters (1982), "Efficiency and Equalization Payments in a Federal System of Government", Canadian Journal of Economics, 15, 613-33.

Bolton, P. and G. Roland (1997), "The Break-Up of Nations: A Political Economy Analysis", Quarterly Journal of Economics, 112, 1057-1090.

Bucovetsky, S. (1991), "Asymmetric Tax Competition," Journal of Urban Economics, 30, 167-181.

Bucovetsky, S. (1995) "Rent Seeking and Tax Competition," Journal of Public Economics, 58, 337-63.

Burbidge, J.B. and G.M. Myers (1994), "Population Mobility and Capital Tax Competition," Regional Science and Urban Economics, 24, 441-459.

Cremer, H. and P. Pestieau (1996), "Distributive Implications of European Integration," European Economic Review, 40, 747-757.

Edwards, J. and M. Keen (1996), "Tax Competition and Leviathan," European Economic Review 40, 113-134.

Epple, D. and T. Romer (1991), "Mobility and Redistribution", Journal of Political Economy, 99, 828-58.

Flatters, F., V. Henderson, and P. Mieszkowski (1974), "Public Goods, Efficiency and Regional Fiscal Equalization," Journal of Public Economics 3, 99-112.

Gordon, R.H. (1983), "An Optimal Taxation Approach to Fiscal Federalism," Quarterly Journal of Economics, 98, 567-586.

Keen, M. (1987), "Welfare Effects of Commodity Tax Harmonization," Journal of Public Economics, 41, 335-350.

Kuhn, P. and I. Wooton (1987), "International Factor Movements in the Presence of a Fixed Factor," Journal of International Economics, 23, 123-140 
Laurel, D. and M. Le Breton (1998), "Existence of Nash Equilibria In Fiscal Competition Models," Regional Science and Urban Economics, 28, 283-296.

Myers, G.M (1990), "Optimality, Free Mobility, and the Regional Authority in a Federation," Journal of Public Economics, 43, 107-121.

Oates, W. E. (1972), Fiscal Federalism, New York: Harcourt Brace Jovanovich.

Perotti, R. (1993), Political Equilibrium, Income Distribution, and Growth, Review of Economic Studies, 60, 755-776.

Persson, T. and G. Tabellini (1992), "The Politics of 1992: Fiscal Policy and European Integration," Review of Economic Studies, 59, 689-701.

Scharf, K. and C. Perroni (1999), Tiebout with Politics: capital Tax Competition and Constitutional Choices, Review of Economic Studies, forthcoming.

Sinn, H.W. (1994), " How Much Europe? Subsidiarity, Centralization, and Fiscal Competition," Scotish Journal of Political Economy, 41, 85-107

Tiebout, Ch. (1956), "A Pure Theory of Local Expenditures", Journal of Political Economy, 64, 416-24.

Wellisch, D. (1999), Theory of Public Finance in a Federal State, Cambridge; Cambridge University Press, in press.

Wildasin, D. (1988), "Nash Equilibria in Models of Fiscal Competition," Journal of Public Economics, 35, 229-240.

Wildasin, D. (1991), "Income Redistribution in a Common Labor Market," American Economic Review, 81, 757-774.

Wilson, J.D. (1987), "Trade, Capital Mobility, and Tax Competition," Journal of Political Economy, 95, 835-856.

Wilson, J.D. (1991), "Tax Competition with Interregional Differences in Factor Endowments," Regional Science and Urban Economics, 21, 423-451. 
Wilson, J.D. (1999), "Theories of Tax Competition," National Tax Journal, forthcoming.

Zodrow, G.R. and P. Mieszkowski (1986), "Pigou, Tiebout, Property Taxation, and the Underprovision of Local Public Goods," Journal of Urban Economics, 19, 356-370. 


\section{Appendix}

Claim: The policy $\left(t_{j}^{*}, g_{j}^{*}\right)$ that is most preferred by the individual with the median capital endowment $k_{j}^{m}$ in country $j$ is the unique majority voting equilibrium in this country.

Proof: Under our assumption that voters are myopic with respect to their own moving decision (or, alternatively, if they vote under the veil of ignorance), only their capital endowment $k^{i}$ matters for their preferred policy. The utility (4) of a voter with endowment $k^{i}$ in country $j$ given a fiscal policy $\tau=\left(t_{j}, g_{j}\right)$ can be written as

$$
c_{j}^{i}(\tau)=c_{j}^{m}(\tau)+\rho_{j}(\tau)\left(k_{j}^{i}-k_{j}^{m}\right),
$$

where $c_{j}^{m}(\tau)$ is the utility (consumption) of the voter with the median capital endowment $k_{j}^{m}$. Now let $\tau$ and $\tau^{\prime}$ be two different policies and assume without loss of generality that this individual prefers policy $\tau$ to policy $\tau^{\prime}$, i.e. $c_{j}^{m}(\tau) \geq c_{j}^{m}\left(\tau^{\prime}\right)$. Using (19), this implies

$$
c_{j}^{i}(\tau)-c_{j}^{i}\left(\tau^{\prime}\right) \geq\left[\rho_{j}(\tau)-\rho_{j}\left(\tau^{\prime}\right)\right]\left(k_{j}^{i}-k_{j}^{m}\right) .
$$

By inspection of $(20), \rho_{j}(\tau) \geq \rho_{j}\left(\tau^{\prime}\right)$ implies $c_{j}^{i}(\tau) \geq c_{j}^{i}\left(\tau^{\prime}\right)$ for all $i$ such that $k^{i} \geq k_{j}^{m}$ and $r_{j}(\tau) \leq r_{j}\left(\tau^{\prime}\right)$ implies $c_{j}^{i}(\tau) \geq c_{j}^{i}\left(\tau^{\prime}\right)$ for all $i$ such that $k^{i} \leq k_{j}^{m}$. In both cases, a majority prefers policy $\tau$ to $\tau^{\prime}$. Observe that the converse is also true, i.e., if a majority of the population prefers $\tau$ to $\tau^{\prime}$, then $c_{j}^{m}(\tau) \geq c_{j}^{m}\left(\tau^{\prime}\right)$. Hence, a policy $\tau$ is preferred to all other policies $\tau^{\prime}$ under majority voting in country $j$ if and only it is the most preferred policy of the individual with median capital endowment $k_{j}^{m}$.

Derivation of the Investment and Migration Responses (Section 3)

Total differentiation of (IE) and (ME) yields the following system of equations:

$$
\left(\begin{array}{cc}
F_{k n}^{1}+F_{k n}^{2} & F_{k k}^{1}+F_{k k}^{2} \\
x_{n}^{1}+x_{n}^{2}-\theta & x_{k}^{1}+x_{k}^{2}
\end{array}\right)\left(\begin{array}{c}
d n_{j} \\
d K_{j}
\end{array}\right)=\left(\begin{array}{c}
1 \\
-k_{j}
\end{array}\right) d t_{j}
$$

where $x_{n}^{j}$ is defined as in Section 2.3. and $x_{k}^{j} \equiv \frac{\partial x_{j}}{\partial K_{j}}=\frac{1}{n_{j}} t_{j}-F_{k k}^{j} k_{j}>0$. Let $D \equiv$ $\left(F_{k n}^{1}+F_{k n}^{2}\right)\left(x_{k}^{1}+x_{k}^{2}\right)-\left(F_{k k}^{1}+F_{k k}^{2}\right)\left(x_{n}^{1}+x_{n}^{2}-\theta\right)$ be the determinant of the matrix of the left hand side. In what follows, we confine ourselves to those equilibria described by (IE) and (ME) that are stable and thus, we must have $D<0$. Using Cramer's rule and substituting the expressions for $x_{n}^{j}$ and $x_{k}^{j}$ yields (14) and (15).

If countries are symmetric and set identical tax rates $t_{1}=t_{2}=t$, we must have $K_{j}=\frac{1}{2} \bar{k}$, $L_{j}=\frac{1}{2} \bar{l}$, and $n_{j}=\frac{1}{2}$ which also implies $k_{j}=\bar{k}$ and $l_{j}=\bar{l}$ in the investment and migration equilibrium. From (14) and (15), we find for $t \geq 0$,

$$
\left.\frac{\partial n_{j}}{\partial t_{j}}\right|_{t_{j}=t}=4 t / D \leq 0,\left.\quad \frac{\partial K_{j}}{\partial t_{j}}\right|_{t_{j}=t}=4\left(g+\frac{1}{4} \theta\right) / D<0
$$

and

$$
D=4 F_{k k}\left(2 g+\frac{1}{2} \theta+2 t \frac{F_{k n}}{F_{k k}}\right)=8 F_{k k}\left(\pi \bar{l}+\frac{1}{4} \theta-t \frac{F_{k l}}{F_{k k}} \bar{l}\right)<0,
$$


where all functions are evaluated at the symmetric factor endowments and the last equality follows from substituting $g=t \bar{k}+\pi \bar{l}$ and using $F_{k n}=-F_{k k} \bar{k}-F_{k l} \bar{l}$ (factor prices adjust to maintain zero profits). Inserting the expression for $D$ into the expressions for $\frac{\partial n_{j}}{\partial t_{j}}$ and $\frac{\partial K_{j}}{\partial t_{j}}$ yields (17) and (18).

Proof of Proposition 3

Setting (16) equal to zero and using our usual notation, the first-order conditions are

$$
\left(1-\sigma_{j}\right)\left(k_{j}-k_{j}^{m}\right)+t_{j} \eta_{k}^{j}-\frac{1}{n_{j}} \pi_{j} l_{j} \eta_{n}^{j}=0 .
$$

Symmetry implies $\sigma_{j}=\frac{1}{2}, \eta_{n}^{j}=\eta_{n}$ and $\eta_{k}^{j}=\eta_{k}$ at $t_{j}=t^{*}$. Furthermore, $n_{j}=\frac{1}{2}, l_{j}=\bar{l}$, $k_{j}=\bar{k}$. Inserting the expressions for $\eta_{k}$ and $\eta_{n}$ as derived in the text into this condition, we find

$$
\frac{1}{2}\left(\bar{k}-k^{m}\right)=-\frac{\theta t^{*}}{F_{k k}\left[\bar{l}\left(\pi-t^{*} \frac{F_{k l}}{F_{k k}}\right)+\frac{1}{4} \theta\right]},
$$

which defines the common equilibrium tax rate $t^{*}$. Holding everything else constant, note first that $\theta \rightarrow \infty$ implies that right hand side of $(21) \rightarrow \frac{t}{4 F_{k k}}$ and (21) reduces to the corresponding equilibrium condition in the pure tax competition case where labour is immobile. Next, observe that the right hand side of (21) increases in both $\theta$ and $t^{*}$. Consider now an equilibrium for which $\rho^{*}>0 \Leftrightarrow t^{*}<r^{*}=F_{k}$, where $F_{k}$ is evaluated at $K_{j}=\frac{1}{2} \bar{k}, L_{j}=\frac{1}{2} \bar{l}$ and $n_{j}=\frac{1}{2}$ [in the proof of Proposition 4 (Step 3) we show that there can be no equilibrium in which the economy wide capital stock is not fully utilitized]. Because all other variables do not vary with $\theta$ or the common tax $t$ in a symmetric equilibrium, we can find for any $\theta^{\prime}<\theta$ a tax rate $t^{\prime}>t^{*}$ such that $(21)$ holds at $\theta^{\prime}$ and $t^{\prime}$. Therefore, if $\rho^{\prime}=r^{*}-t^{\prime} \geq 0$, there exists a new equilibrium satisfying (21) with $t^{\prime}>t^{*}$. If $\rho^{\prime}<0$, i.e., $t^{\prime}>r^{*}$, let the new equilibrium tax rate be $t^{\prime \prime}=r^{*}$. In either case, $t^{*}\left(\theta^{\prime}\right)>t^{*}(\theta)$ and the fall in $\theta$ strictly improves the welfare of a majority of the voting population in each country by the same argument as in the proofs of Propositions 1 and 2. Finally, note that $\theta \rightarrow 0$ implies that RHS $\rightarrow 0$, i.e. we approach full taxation for some $\theta>>0$.

Proof of Proposition 4

For the proof of this proposition, the following lemma is useful:

Lemma 1. Suppose $\theta=0$. Then, for $j, h \in\{1,2\}, j \neq h$, we have

$$
\begin{aligned}
& t_{j}=t_{h} \quad \Longrightarrow \quad k_{j}=k_{h} \quad \text { and } \quad l_{j}=l_{h} ; \\
& t_{j}<t_{h} \Longrightarrow k_{j}>k_{h} \quad \text { and } \quad l_{j} \leq l_{h},
\end{aligned}
$$

with strict inequality if $t_{j}>0$.

Proof. Let $f_{j}=f\left(k_{j}, l_{j}\right)$ be the per-capita production in country $j$. Since $f(\cdot)$ is concave,

$$
f_{j}-f_{h} \geq f_{k}^{j}\left(k_{j}-k_{h}\right)+f_{l}^{j}\left(l_{j}-l_{h}\right), \quad j, h=1,2 .
$$


For $\theta=0$, the migration equilibrium condition (ME) can be written as $f_{j}-f_{h}=\rho\left(k_{j}-k_{h}\right)$. Inserting this equation into the inequality above, setting $f_{l}^{j}=\pi_{j}$ and $\rho=\left(f_{k}^{j}-t_{j}\right)$ yields $t_{j}\left(k_{j}-k_{h}\right)+\pi_{j}\left(l_{j}-l_{h}\right) \leq 0, j, h=1,2$, or, equivalently

$$
\text { and } \begin{aligned}
t_{1}\left(k_{1}-k_{2}\right) & \leq \pi_{1}\left(l_{2}-l_{1}\right) \\
t_{2}\left(k_{1}-k_{2}\right) & \geq \pi_{2}\left(l_{2}-l_{1}\right) .
\end{aligned}
$$

Consider first $t_{1}=t_{2}$ and suppose without loss of generality that $k_{1}>k_{2}$. Because $f_{k}^{j}$ is decreasing in $k$ and increasing in $l$, the investment equilibrium condition (IE) then implies $l_{1}>l_{2}$, which together with $k_{1}>k_{2}$ contradicts (24). Hence, for $t_{1}=t_{2}$, we must have $k_{1}=k_{2}$ and $l_{1}=l_{2}$.

Next, consider $t_{1}<t_{2}$ and suppose $k_{1} \leq k_{2}$ (the case $t_{2}<t_{1}$ is analogous). (IE) then implies $l_{1}<l_{2}$. But $k_{1} \leq k_{2}$ and $l_{1}<l_{2}$ contradict (25). Thus, we must have $k_{1}>k_{2}$ which together with (24) implies $l_{1} \leq l_{2}$ with strict inequality if $t_{1}>0$.

Step 1: For $\theta \rightarrow 0$ and $k_{j}^{m}<\bar{k}, j=1,2$, asymmetric equilibria cannot exist.

The proof uses a revealed preference argument and is by contradiction. Thus, suppose there exist an equilibrium with asymmetric tax rates and assume $t_{1}^{*}<t_{2}^{*}$ without loss of generality. If this is an equilibrium, the median-income individual in country 1 must weakly prefer $t_{1}^{*}$ to any other tax rate. In particular this must be true for the equilibrium tax rate in the foreign country, $t_{2}^{*}$. From Lemma 1 , if $t_{1}=t_{2}^{*}, k_{1}=k_{2}=\bar{k}$ and $l_{1}=l_{2}=\bar{l}$. Hence,

$$
c_{1}^{m}\left(t_{1}^{*}, t_{2}^{*}\right)=f_{1}^{*}-\rho^{*}\left(k_{1}^{*}-k_{1}^{m}\right) \geq \bar{f}-\bar{\rho}\left(\bar{k}-k_{1}^{m}\right)=c_{1}^{m}\left(t_{2}^{*}, t_{2}^{*}\right),
$$

where $\bar{f}=f(\bar{k}, \bar{l})$ and $\bar{\rho}=f_{k}(\bar{k}, \bar{l})-t_{2}^{*}$. From the migration equilibrium, $f_{1}^{*}-\rho^{*} k_{1}^{*}=f_{2}^{*}-\rho^{*} k_{2}^{*}$. Inserting this expression into (26) yields

$$
f_{2}^{*}-\rho^{*}\left(k_{2}^{*}-k_{1}^{m}\right) \geq \bar{f}-\bar{\rho}\left(\bar{k}-k_{1}^{m}\right)
$$

Multiplying (26) by $n_{1}$ and (27) by $n_{2}$ and adding the two, we find

$$
n_{1} f_{1}^{*}+n_{2} f_{2}^{*}-\rho^{*}\left(\bar{k}-k_{1}^{m}\right) \geq \bar{f}-\bar{\rho}\left(\bar{k}-k_{1}^{m}\right) .
$$

Note that $\bar{f} \geq n_{1} f_{1}+n_{2} f_{2}$ because total output is maximized for $k_{j}=\bar{k}$ and $l_{j}=\bar{l}, j=1,2$. Hence, the above inequality can be satisfied only if $\rho^{*}\left(\bar{k}-k_{1}^{m}\right) \leq \bar{\rho}\left(\bar{k}-k_{1}^{m}\right)$. Due to $\bar{k}>\bar{k}_{1}^{m}$ by assumption, this is equivalent to $\rho^{*} \leq \bar{\rho}$ or, using the expressions $\rho^{*}=f_{k}\left(k_{2}^{*}, l_{2}^{*}\right)-t_{2}^{*}$ and $\bar{\rho}=f_{k}(\bar{k}, \bar{l})-t_{2}^{*}$, to

$$
f_{k}\left(k_{2}^{*}, l_{2}^{*}\right) \leq f_{k}(\bar{k}, \bar{l}) .
$$

From Lemma 1 , however, $t_{1}^{*}<t_{2}^{*}$ implies $k_{1}^{*}>k_{2}^{*}$ and $l_{1}^{*} \leq l_{2}^{*}$. Hence, $k_{2}^{*}<\bar{k}$ and $l_{2}^{*}>\bar{l}$, a contradiction to $(28)$.

Step 2: Next, we show that for $k_{j}^{m}<\bar{k}, j=1,2$, there exists a unique equilibrium in which $t_{j}^{*}=\bar{r}=f_{k}(\bar{k}, \bar{l})$. We already know from Step 1 that any equilibrium must be symmetric. Evaluating the migration and investment response functions at their (symmetric) equilibrium values [see (equations in text)] and setting $\theta=0$, we find

$$
\left.\frac{\partial c_{j}^{m}}{\partial t_{j}}\right|_{t_{j}=t_{h}}=\bar{k}-k_{j}^{m}>0,
$$


for any $t_{j}=t_{h}$ such that $n_{1} k_{1}+n_{2} k_{2}=\bar{k}$. Hence, a majority of voters in country $j$ would prefer a higher tax rate than $t_{h}$ for $t_{h}<\bar{R} \Leftrightarrow r>0$. Conversely, for symmetric tax rates where $\rho=0$ and $n_{1} k_{1}+n_{2} k_{2}<\bar{k}, \frac{\partial c_{j}^{m}}{\partial t_{j}}<0$ and a majority of voters prefers a lower tax than $t_{h}$ (see below). It follows that the unique equilibrium is $t_{j}^{*}=\bar{r}, j=1,2$ which completes the proof.

Step 3: It remains to show that there can be no equilibrium in which the economy's capital stock is not fully utilized, i.e. where $n_{1} k_{1}+n_{2} k_{2}<\bar{k}$. We will verify this claim for any arbitrary $\theta \geq 0$ and $t_{1}, t_{2}$ (and so it must be true for $\theta=0$ and $t_{1}=t_{2}$ as well). Consider a situation where $t_{1}$ and $t_{2}$ are such that $\rho\left(t_{1}, t_{2}\right)=0$ and $n_{1} k_{1}+n_{2} k_{2}<\bar{k}$. From the investment equilibrium, $F_{k}^{j}-t_{j}=0$ so that changes in the domestic tax rate $t_{j}$ correspond to changes in $F_{k}^{j}$ and do not affect the return to capital $F_{k}^{h}$ abroad. Also observe that because $F_{k}^{j}$ is homogeneous of degree zero, we can write $r_{j}=F_{k}\left(K_{j}, L_{j}, n_{j}\right)=F_{k}\left(k_{j}, l_{j}, 1\right)$ so that $d F_{k}^{j}=F_{k k}^{j} d k_{j}-\frac{1}{n_{j}} l_{j} F_{k l}^{j} d n_{j}$. Setting $d F_{k}^{j}=d t_{j}$ and $d F_{k}^{h}=0$ and using $d n_{h}=-d n_{j}$, we find

$$
F_{k k}^{j} \frac{d k_{j}}{d t_{j}}-\frac{1}{n_{j}} F_{k l}^{j} l_{j} \frac{d n_{j}}{d t_{j}}=1 \quad \text { and } \quad F_{k k}^{h} \frac{d k_{h}}{d t_{j}}+\frac{1}{n_{h}} F_{k l}^{h} l_{h} \frac{d n_{j}}{d t_{j}}=0
$$

This implies

$$
\frac{d n_{j}}{d t_{j}} \geq 0 \quad \Rightarrow \quad \frac{d k_{j}}{d t_{j}}<0 \quad \text { and } \quad \frac{d n_{j}}{d t_{j}} \geq 0 \quad \Leftrightarrow \quad \frac{d k_{h}}{d t_{j}} \geq 0 .
$$

Next, observe that since $\rho=0$ the consumption of a voter in $j$ is $c_{j}^{i}=y_{j}=\frac{1}{n_{j}} F\left(k_{j}, l_{j}, 1\right)$ for all $i$. Totally differentiating the migration equilibrium condition $c_{j}^{i}=c_{h}^{i}-\theta\left(\bar{n}_{j}-n_{j}\right)$ then yields,

$$
\frac{d c_{j}^{i}}{d t_{j}}=\frac{d c_{h}^{i}}{d t_{j}}+\theta \frac{d n_{j}}{d t_{j}}=F_{k}^{h} \frac{d k_{h}}{d t_{j}}+\left(\frac{1}{n_{h}} l_{h} F_{l}^{h}+\theta\right) \frac{d n_{j}}{d t_{j}}
$$

We want to show that $d c_{j}^{i} / d t_{j}$ is strictly negative, that is, the voters in $j$ unanimously prefer to lower their tax rate in such a situation. Suppose by way of contradiction that $d c_{j}^{i} / d t_{j} \geq 0$ so that the right hand side of (30) is non-negative. Together with the second expression in (29), this requires $d n_{j} / d t_{j} \geq 0$ and $d k_{h} / d t_{j} \geq 0$. But the first expression in (29) then implies $d k_{j} / d t_{j}<0$; a contradiction to our assumption that $d c_{j}^{i} / d t_{j} \geq 0$ because $c_{j}^{m}$ strictly decreases in $n_{j}$ and strictly increases in $k_{j} . \square$ 